\title{
Localizando as condições pretéritas e as relações correntes na complexa fronteira Brasil-Bolívia*
}

\author{
Tito Carlos Mac hado Oliveira** \\ Paulo Marcos Esselin***
}

\section{Resumo}

A fronteira Brasil-Bolívia, na parte mais ao sul, teve papel importante no abastecimento do oeste brasileiro através dos rios da Bacia do Prata no início do sec. XX, nos anos cinquenta ensaiou um processo de industrialização, até se transformar em uma rica fronteira vibrante no final do século. Repleta de ambiguidades, porosidades e deslizamentos a fronteira conurbada de CorumbáLadário-Puerto Qijarro-Puerto Suarez tem demonstrado um rico processo de integração socioeconômica e uma complexa rede de relações sociais e institucionais. Este texto tem a intensão de localizar as condições pretéritas da fronteira Brasil-Bolívia e contextualizar as relações cotidianas daquela conurbação fronteiriça, sob a tutela metodológica da historiografia e da categoria território da ciência geografia. É parta do projeto de pesquisa "Polos geográficos de ligação" com financiamento da Fundect e do CNPq até 2016.

** Parte do Projeto de pesquisa "Polos de geográficos de ligação" com financiamento do CNPq e da Fundect.

**** Professor da Universidade Federal do Mato Grosso do Sul (tito.machado@ufms.br).

****** Professor da Universidade Federal do Mato Grosso do Sul (paulo.esselin@gmail.com)

Geosul, Florianópolis, v. 30, n. 60, p 125-163, jul./dez. 2015 
OLIVEIRA, T.C.M. \& ESSELIN, P.M. Localizando as condições pretéritas...

Palavras-chaves: Fronteira Brasil-Bolívia; Conurbação fronteiriça; Integração.

Locating preterit conditions and current relations of the complex Brazil-Bolivia border

\begin{abstract}
The Brazil-Bolivia border, in the southernmost, played an important role in western Brazil supply through La Plata River Basin in the early $20^{\text {th }}$ century, attempted an industrialization process in the fifties to become a rich vibrant border at the end of century. Full of ambiguities, porosities and slipping the frontier conurbation of Corumbá/Ladário-Puerto Quijarro/Puerto Suárez exhibited a valued process of socioeconomic integration and a complex network of social and institutional relations. This text intends to find preterit conditions of Brazil-Bolivia border and contextualize daily relations that frontier conurbation, under methodological regard of the historiography and territory class of geography science. It is part of the project "Connections geographical poles" with funding from Fundect and CNPq to 2016. Key words: Brazil-Bolivia border; Frontier conurbation; Integration.
\end{abstract}

\title{
Localizando o ambiente - uma introdução
}

Corumbá é uma bela cidade com mais de dois séculos de vida, cravada no meio do Pantanal do Mato Grosso do Sul, na fronteira com a Bolívia, às margens do Rio Paraguai, iluminada na latitude de capricórnio, com baixa altitude $(120 \mathrm{~m})$, assentada sobre uma laje de rocha calcária, o que a torna severamente quente e úmida (mesmo com baixa pluviosidade) durante o dia e a noite. 
OLIVEIRA, T.C.M. \& ESSELIN, P.M. Localizando as condições pretéritas...

Possui um sítio urbano planejado há mais de 150 anos, com ruas largas, e no qual se misturam arquiteturas modernas rodeadas por prédios que remontam a passagem do séc. XIX para o XX.Deslocando-se para o lado leste por uma rua às margens do Rio Paraguai encontra-se Ladário, cidade conurbada, igualmente histórica. Seguindo para o poente, margeando a Baía do Tamengo chega-se a Bolívia. Primeiramente em Arroyo Concepción, poucos quilômetros a direita de quem ingressa depara-se com Puerto Quijarro, porém, seguindo-se em frente alguns quilômetros adentra a cidade de Puerto Soares, capital da Província de German Bush.

São cinco localidades que formam uma juntura conurbada (Figura 1) de grande articulação social e interação econômica. É um território de configuração estratégica por ser o principal ponto de contato entre o Brasil e a Bolívia. Por ali passa o gasoduto e um amontoado de mercadorias outras (chegam ou partem) utilizando o rio, as rodovias e as ferrovias que se aproximam. Soma-se a esta malha, uma estrutura física com grande reserva de minério de ferro e manganês nas morrarias do Urucum e Jacadigo no lado brasileiro e Mutum na Bolívia.

Nas proximidades de quase 170 mil habitantes, esse território conduz um extravagante movimento de fluxos de mercadorias e transeuntes que causa frisson em qualquer observante, ainda que desatento. Gás, minério, turismo, exportação e reexportação aludem um vai e vem de barcos e barcaças no rio, acenam com um transbordo de passageiros terrestres nos taxis adaptados, nas diversas linhas de coletivos intermunicipal, interestadual e internacional, um formigueiro de veículos (carros, motos e similares) que passa e repassa a fronteira comprando e vendendo roupas, verduras, brinquedos, bebidas, fraldas, serviços desorientando o trânsito e cosmopolizando passeios, praças e feiras 
OLIVEIRA, T.C.M. \& ESSELIN, P.M. Localizando as condições pretéritas...

deixando atordoado qualquer observador, sem fôlego o leitor e sem regras e sem respeito gramatical qualquer relator.

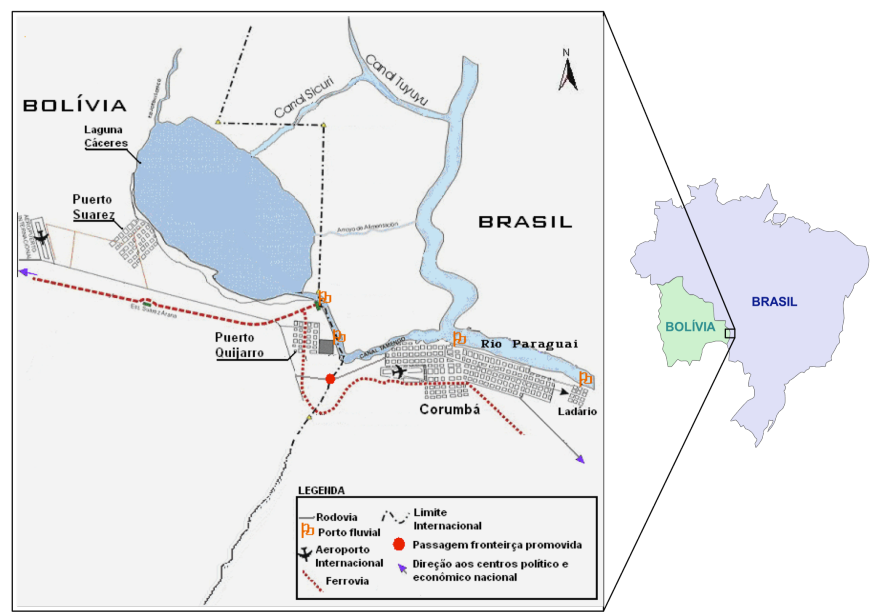

Figura 1: Localização da Conurbação (Corumbá-Ladário-Puerto Quijarro-Puerto Soares).

Este pedaço sul da fronteira Brasil-Bolívia somente foi construída, contundentemente, a partir das últimas duas décadas do século passado.

Este texto tem a intenção de localizar as condições pretéritas da fronteira Brasil-Bolívia e contextualizar as relações cotidianas da complexa junção de Corumbá-Puerto Suarez-Puerto QuijarroLadário, sob a tutela metodológica da historiografia e da categoria território da ciência geográfica.

\section{Localizando as condições pretéritas - a fronteira distante}


OLIVEIRA, T.C.M. \& ESSELIN, P.M. Localizando as condições pretéritas...

Entre o final do século XIX e início do século XX a cidade de Corumbá era, sobretudo, um centro importador de mercadorias da Europa (sobretudo) para dentro do velho Matto Grosso. Aproveitando da facilidade de navegação com navios de grande e médio calado pelo Rio Paraguai, esta cidade se transformou em um entreposto comercial entre a jusante e a montante do grande rio ${ }^{1}$; ali o capital fez sua morada com uma circulação que desafiou os limites geográficos e históricos (Alves, 1985).

A ausência de mão de obra nas sesmarias pantaneiras, mesmo que utilizando o labor indígena, não se colocava como suficiente para taxiar uma substantiva economia natural em seu núcleo, praticamente tudo a fazenda consumia de fora, até mesmo a pequena agricultura e a pequena criação de animais estava jugulada pelo meio geográfico. Ou seja, a divisão técnica do trabalho estava relacionada ao fator criatório do gado. Como efeito, a ausência de produção interna reforçava a necessidade de comprar todos os apetrechos necessários a pecuária e às lides domesticas.

Por outro lado, a segunda Revolução Industrial no centro dinâmico da economia mundial (Estados Unidos e Alemanha à frente), final do séc. XIX, suscitou um movimento dos fluxos de mercadorias sem precedente, somente superada nos anos oitenta do século passado. Como medida de apoio ao desenvolvimento comercial de Corumbá, o governo imperial baixou o Decreto $\mathrm{n}^{\mathrm{o}}$ 4.388de 15 de agosto de 1869, isentando de tributação todos os gêneros de importação e exportação comercializados naquela praça por um período de dois anos e liberou o porto corumbaense para a entrada de todas as embarcações de diversas origens, como forma

1 De Corumbá para Cáceres rio acima as embarcações deveriam ser, obrigatoriamente, de baixo calado. 
OLIVEIRA, T.C.M. \& ESSELIN, P.M. Localizando as condições pretéritas...

de tornar a região mais independente dos recursos da Corte (CORRÊA, 1981).

O trânsito de navios - ainda a vapor - fez de Corumbá o principal centro abastecedor de todo velho Mato Grosso, que também exportava, ainda que sem significado, couro vacum, charque e algumas peles de animais silvestres; Corumbá rapidamente se transformou em um forte porto fluvial da América Latina.

Nesse contexto, há o primeiro problema: existia ali um sentido de combinações adversas. Todo, ou a maioria absoluta do gado produzido no Pantanal estava comprometido com o mercado interno desde a metade do século XIX, ainda que houvessem charqueadas e saladeiros com pauta de exportação. Isto é, Corumbá e região possuíam comunicação de mão única com dois lados: um lado interno ligado, quase unicamente, a saída de produtos (gado) para o oeste paulista; e um lado externo ligado à entrada de produtos do mercado mundial. Esse fator que poderia se tornar um elemento de desenvoltura para a economia regional, caso respaldasse uma interação de trocas efetivas com ambos os lados; se tornou um problema a partir do momento em que um dos lados se distanciou.

Esse movimento que regulava a importação de mercadorias europeias e abastecimento de gado para o mercado nacional terminava por combinar formas e interesses muito diferente (antagônicas até) de produção de excedentes. O resultado foi a consolidação de duas classes dominantes com contornos políticos e metodológicos díspares: os comerciantes dos portos (ligados ao mercado externo), e os latifundiários pantaneiros (ligados ao oeste paulista), passam a povoar o ambiente político administrativo regional.

Considerando toda a dinâmica existente, é possível constatar que a atmosfera favorecia muito mais os comerciantes do que os latifundiários. Por atuarem no setor comercial e creditício com interlocuções mais avançadas com capitalismo mais moderno, os 
OLIVEIRA, T.C.M. \& ESSELIN, P.M. Localizando as condições pretéritas...

comerciantes sustentavam um processo de acumulação de capital em ritmo, grau e intensidade superior aos latifundiários, et pour cause, terminavam por engendrar uma cadência de convivência urbana que lhes garantia capacidade de intervenção, prestigio e poder.

Por esta ocasião, mesmo o pantanal apresentando um ritmo de crescimento muito substantivo do rebanho, associado aos reduzidos gastos com o manejo do gado dado pelas as propriedades do terreno; e, mesmo que o mercado paulista estivesse em ascensão, o mercado nacional ainda encontrava-se em estágio embrionário, com uma malha frágil que dificultava uma rede de articulação mais interligada.

Esses ingredientes apontavam para um procedimento moroso entre $\mathrm{o}$ ato de criar o rebanho, transportar o gado, realizar o negócio e desfrutar do dinheiro. Somente um nó seria capaz de atar as diversas pontas e assegurar a continuidade da produção pecuária: o crédito nas mãos dos comerciantes.

Resultado: vários pecuaristas vão caindo nas teias das taxas creditícias da casa comercial ${ }^{2}$ dos comerciantes dos portos (Alves, 1985). É a chegada do Banco do Brasil em 1916 quem libertará os combalidos pecuaristas das relações creditícias ali estabelecidas.

A geografia econômica do primeiro quartel do século XX não foi benevolente com aquela fronteira. Primeiramente porque há uma retração rigorosa na produção e circulação de mercadorias no centro dinâmico da economia mundial após o início da Primeira Grande Guerra, especialmente depois da transformação de parte da frota comercial inglesa em frota para guerra (navios-hospitais, navios-

2 É bom lembrar que, ainda que aparente esta função creditícia da casa comercial, apenas na aparência consistia em ser capital financeiro, na realidade era "comércio de dinheiro", um dos atributos do capital mercantil, ainda que tivesse conexões íntimas com bancos europeus este serviço não correspondia ao conteúdo teórico de um capitalismo financeiro. 
OLIVEIRA, T.C.M. \& ESSELIN, P.M. Localizando as condições pretéritas...

oficinas, transporte de tropas, navios-de-carvão para reabastecimento), encarecendo os produtos que chegaram a Corumbá. Segundo: o nascimento de indústrias substitutivas de importações no sudeste (São Paulo em especial) consolidando, já na década de vinte, um "centro dinâmico da economia brasileira" (Cf. FURTADO, 1954) forçava novos caminhos para o abastecimento do velho Mato Groso.

Essas duas condições, apenas para não aprofundar em outras, conspiravam definitivamente contra a condição regional de Corumbá: ao mesmo tempo em que os produtos economia mundial se tornavam rarefeitos e caros; as mercadorias produzidas no Sudeste faziam de Campo Grande um novo centro distribuidor e intermediador entre a metrópole (paulistana) e o sertão (matogrossense). Corumbá, nestes termos, sucede os anos seguintes como força centrífuga, enquanto Campo Grande se consolida como força centrípeta. Várias famílias: Fragelli, Calarge, Sayad, Said, Mandeta, Trad, entre outras, todas de comerciantes migrantes capitalizados foram sugados para Campo Grande.

A condição fronteiriça, nessa época, estava presa aos meandros do rio Paraguai; e através deste apresentava relações estreitas com o Paraguai, Uruguai e Argentina; era por esta passagem que ocorria uma substantiva migração: no início do século XX, Corumbá, segundo Oliveira (2005), contava com mais de vinte e cinco nacionalidades.

A Bolívia, ao lado, era senão, um território muito distante quase sem lastro ${ }^{3}$. Havia uma distância geográfica em centenas de quilômetros que separava a fronteira de Santa Cruz de la Sierra, a

${ }^{3}$ Puerto Suares era, na época, uma pequena vila fundada em 1875 que se ligava a Corumbá basicamente pelo canal do Tamengo e Laguna Cáceres, onde em 1900 foi construído uma cais para embarcações de pequeno calado. 
OLIVEIRA, T.C.M. \& ESSELIN, P.M. Localizando as condições pretéritas...

cidade mais importante da Bolívia fora dos Andes; mais algumas centenas de quilômetros de Campo Grande e mais de mil de Cuiabá a capital do velho Mato Grosso, diminuindo-se possíveis iniciativas de enlaces comerciais; entre Corumbá e Puerto Suarez havia onze quilômetros de distância, e no meio do caminho estava o arroio Concepción, à época caudaloso e sem ponte, fazia com que a pouca circulação existente entre as cidades fosse atingida com dificuldades; era também preciso considerar o distanciamento cultural, comportamental e linguístico existente entre os povos viventes naquela região.

E, havia ainda uma distância diplomática imposta pela sombra do Tratado de Petrópolis ${ }^{4}$ que consumia as possibilidades de aproximação física entre as duas partes da fronteira. De modo que, as relações eram prejudicadas em todos os sentidos: físicos, diplomáticos e culturais. Localizando aquele pedaço da fronteira brasileira com a Bolívia como "Fronteira Distante" na tipologia de Oliveira (2009) ${ }^{5}$.

Todavia, toda esta cerca de limitações não impediu o nascimento de relações de aproximação entre Corumbá e Porto Suarez, alguma comunicação já estava presente:

4 O Tratado de Petrópolis, firmado em 18 de novembro de 1903 foi na opinião de Bandeira (2000) uma compra disfarçada conduzida diplomaticamente e reduziu incertezas e controvérsias sobre os limites territoriais, abrandando a intricada "Questão do Acre" e que consolidando a atual fronteira Brasil-Bolívia como ato peremptório.

5 Em "Frontières em Amérique latine: réflexions méthodologiques " Oliveira (2009) identifica quatro tipos de fronteiras na América Latina a partir do cruzamento entre as integrações formais e funcionais: Fronteiras Distantes; Fronteiras Protocolares; Fronteiras Crespas e Fronteiras Vibrantes. 
OLIVEIRA, T.C.M. \& ESSELIN, P.M. Localizando as condições pretéritas...

[...] alli [Puerto Suarez] se compram vários artigos por preços reduzidíssimos, attento o pequeno imposto de importação cobrado pela respectiva aduana. Apezar da vigilância dos empregados da alfândega brasileira reina o contrabando, com grave prejuízo para o commercio de Corumbá (AMORIM, 1917, p.455).

Constatava-se a presença de um pequeno comércio funcional, ainda que minúsculo, entre as cidades, realizado pelas camadas mais pobres da população - o que de certa forma persistiu ao longo do tempo - que desobedeciam as imposições legislativas para enfrentar as difíceis condições cotidianas.

O levantamento realizado por Esselin, Oliveira e Oliveira (2012) junto ao acervo histórico do Fórum da Comarca de Corumbá, pontua que naquele início de século, aparecem crimes com envolvimento de bolivianos sempre em "grau de gravidade muito inferior aos que outros grupos de imigrantes cometiam" ligados a "discussões domésticas", "perturbação a ordem social", "bebedeiras", "fazer necessidades fisiológicas nas ruas", etc; como também constatou, pelos registros da Paróquia de N.S Candelária, que alguns casamentos entre brasileiros e bolivianos na classe mais pobre já aconteciam (p.155). Nesse período de razoável fluxo comercial para os padrões da época, houve ocasiões em que a cidade de Corumbá ficou isolada do mundo durante um mês inteiro, navios não ancoravam no porto, as linhas telegráficas não raras em más condições com a queda de postes devido as enchentes dos rios, obrigavam os moradores daquela localidade a buscar nas cidades bolivianas o que lhes careciam, permitindo, desde modo, estreitar relações comerciais com a Bolívia (AMORIM, 1917).

$\mathrm{Na}$ realidade esta pequena interação entre as populações nasce, em hipótese, somente após o declínio do comercio dos 
OLIVEIRA, T.C.M. \& ESSELIN, P.M. Localizando as condições pretéritas...

portos no segundo lustro da década de dez do século XX. Assim, esta Fronteira marcada pelo distanciamento, passa a cunhar formas de aproximação dando início a um novo desenho do processo.

\section{Localizando as novas condições do pretérito - nasce uma fronteira protocolar.}

Apesar do grande desmonte da economia portuária e a força centrípeta exercida pelo dinamismo de Campo Grande, estabelecendo o fim da era dos comerciantes, tal fato não correspondeu a uma retirada in totun da competência regional que a Corumbá desempenhava, nem tampouco promoveu um debáclé de seus aparelhos urbanos. Nos anos trinta, aquela cidade ainda era, com sobras, a segunda maior arrecadação do Estado, alavancada pela exploração do minério (Lamoso, 2001), pela pecuária (ESSELIN e OLIVEIRA, 2006), pelas charqueadas e pelo transporte ribeirinho (OLIVEIRA, 1998).

$O$ entrave da natureza retardava o nascimento de uma economia natural no seio das fazendas pantaneiras, enquanto o avião, visto como um "pássaro" de luxo, forçava a manutenção e abastecimento pelos rios de todas as propriedades rurais da baixada paraguaia e suas bordas (MICHELS e OLIVEIRA, 2000); longe de representar a mesma pujança do passado, a navegação pela Bacia do Prata e de circulação ribeirinha persistiu até os anos sessenta com muita regularidade. E a economia pantaneira, então, se arrasta até a segunda metade dos anos quarenta.

Na década de quarenta o Grupo Chamma, tradicional grupo sudestino do ramo têxtil, como forma de diversificar suas atividades industriais, resolveu investir no beneficiamento do minério. Por conta, surgiu a Sociedade Brasileira de Mineração (Sobramil) com uma siderurgia no meio do caminho entre 
OLIVEIRA, T.C.M. \& ESSELIN, P.M. Localizando as condições pretéritas...

Corumbá e Ladário, em 1944, iniciando seu funcionamento pleno quatro anos mais tarde. Essa indústria, por duas décadas, será a principal responsável pela mudança da face econômica regional, instaurando uma nova concepção domada por uma nova lógica de acumulação do capital.

Como dito anteriormente, a cidade estava subsistindo da condição pecuária, da navegação pelo Rio Paraguai e do abastecimento intrarregional por pequenas e médias empresas navegadoras (Gattaz, Kassar, Mihanovich, etc.). A implantação da siderurgia não destruiu essa competência da cidade, senão, ampliou-a durante mais alguns anos. Mas, a motricidade dos acontecimentos decorrentes da chegada do capital industrial vai impor uma redefinição da composição orgânica da cidade.

Primeiro, o mais agudo, é o contingente de mão-de-obra absorvido pela Siderurgia. Segundo, aponta Chama (s.d) a empresa foi responsável pelo translado de mais de dois mil trabalhadores do Nordeste, com o intuito de coletar madeira de lenha, ao redor da cidade, para os fornos siderúrgicos. Considerando que a população das duas cidades pouco ultrapassava a vinte mil almas (24 mil urbanos segundo Censo 1950), dois mil novos trabalhadores representavam um acréscimo repentino de quase $10 \%$ a mais no contingente populacional. Este volume passou como efeito, invocar novos limites para o abastecimento. Em que pesem todos os tipos de maus tratos a que foram submetidos - segundo informações de alguns sobreviventes - esses trabalhadores terminavam por representar próximo de $20 \%$ no volume da população economicamente ativa da época. Nada mais natural que fossem concebidas novas formas de implementação do capital na reutilização do potencial financeiro nas mãos daqueles laboriosos.

Noutros termos, elevou-se consideravelmente a capacidade produtiva da economia local. Foram refeitas as contas e as 
OLIVEIRA, T.C.M. \& ESSELIN, P.M. Localizando as condições pretéritas...

possibilidades de investimento em unidades industriais e no comércio de mercadorias de toda espécie; ampliou-se a necessidade de profissionais liberais, de atividades sociais e de prestação de serviços. Isto é, os volumes de capitais investidos na Sobramil passavam a se sobrepor, em cadeia, as tendências multiplicadoras de realocação de novos capitais. Foi, assim, na caminhada de sua produção que a Sobramil deixava em seu rastro, uma série de "combinações inéditas" sobre o tecido urbano que oportunizaram outras atividades econômicas capazes de alterar a identidade produtiva territorial.

Sem embargo, capitais de origem local e de alhures puderam desencadear texturas combinadas de investimentos. Caso típico foi a chegada do Grupo Itaú (Minas Gerais) para exploração das reservas de calcário de excelente qualidade para produção de cimento. Outro caso também muito representativo foi o aproveitamento da capacidade ociosa de até $90 \%$ no trafego de retorno dos navios que desciam o rio com minério até o porto de Nueva Palmira (Uruguai), para trazer trigo da Argentina e que, associado a disponibilidade de capitais nas mãos de comerciantes locais (Kassar, Dolabani, Katurchi, Yasbeck e Sahib), e à facilidade de comprar máquinas no mercado europeu ${ }^{6}$, possibilitou $o$ aparecimento do Moinho Mato-grossense em Corumbá, com máquinas suíças, com alto poder competitivo no Brasil.

No fulcro do sucateamento de máquinas do Sudeste foi que nasceu a Fiação Mato-Grossense. Foi aproveitando a recente

6 O plano de recuperação europeia pós-Segunda Guerra possibilitou a substituição de máquinas e equipamentos, com plena capacidade de uso, por máquinas de última geração, financiadas pelo desenrolar do Plano Marchall. Esse fato possibilitou a disposição para venda das velhas máquinas a custos moderados. 
OLIVEIRA, T.C.M. \& ESSELIN, P.M. Localizando as condições pretéritas...

capacidade de abastecimento regional ${ }^{7}$ que nasceram as caieiras, marmorarias, curtumes, estaleiros; e, os movimentos que faziam crescer a população urbana - pouco mais de vinte mil em 1950 para mais de setenta mil em 1970 - fizeram florescer usina de pasteurização de leite, a maior sorveteria do Estado, indústrias de refrigerantes e cerveja, caieiras, pequenas fábricas de sapato, etc. etc. E, o comércio enquanto nodosidade de todo este processo vivia novamente seu enlevo. O ciclo de seca do Pantanal (1951 a 1973) elevou o rebanho para números estratosféricos de cabeças de gado ${ }^{8}$, fortalecendo economicamente os donos de terras.

Mas: a condição industrial de Corumbá fez e se desfez como febre que não mata. Fatores internos e externos foram determinantes para a derrocada do status de cidade industrial de Corumbá a partir dos últimos anos da década de sessenta: o crescimento e modernização da indústria brasileira no Sudeste; queda dos preços do minério de ferro e manganês; fortalecimento da condição regional da cidade de Campo Grande, entre muitos. O fato é que a cidade passou a se descapitalizar em um ritmo alucinante, cujo mote central foi a redução produtiva da Sobramil até a sua desativação no final dos anos sessenta. De tal modo que, se foi no "rastro" da caminhada industrial da Sobramil que todas as outras indústrias se ancoraram, foi também no "rastro" de seu

7 Corumbá era uma abastecedora natural, ainda que transportasse precariamente, de cimento, cal e trigo para cidades como Coxim, Porto Murtinho, Miranda, Bela Vista, Anastácio, e Aquidauana, destas para outras cidades e para fora do Estado.

8 O crescimento do rebanho de 1950 para 1960, segundo os Censos Econômicos, foi superior a $60 \%$ e de 1960 para 1970 foi de mais de $120 \%$, embora tal fato não representou, em princípio, avanço qualitativo no manejo. 
OLIVEIRA, T.C.M. \& ESSELIN, P.M. Localizando as condições pretéritas...

ocaso que todas (ou quase todas) indústrias entraram numa espiral descendente. Pelo lado rural, o ciclo de cheias do pantanal, a partir de 1973, enfraquece a pecuária (redução do rebanho de 4,98 milhões de cabeça na área compreendida como Pantanal para 3,53 milhões em 1980), aumenta o custo de produção e empobrece pecuaristas, segundo Cadavid, 1981) e, sequencialmente, a frágil navegação ribeirinha recrudesce.

De forma sintética é possível afirmar que havia um problema de escala entre a desenvoltura da estrutura produtiva localizada em Corumbá em relação ao entorno consumidor. A escala de funcionamento do capital ali alocado esta superdimensionado em relação a capacidade de consumo regional, obrigando que os produtos como ferro, trigo, cimento, cal, tecelagem, etc. fossem vendidos para além das divisas do Estado em especial para São Paulo, sem ter efetivo suporte técnico (maquinaria e transporte) que o respaldasse. Bastou um solavanco nas condições produtivas dados pelo "milagre de 1968" nas condições produtivas do Sudeste para que a capacidade competitiva existente desabasse.

Resultado: o desânimo tomou conta da cidade nos anos setenta. Somada a tudo ocorre ainda a divisão do Mato Grosso (outubro de 1977) transformando Campo Grande na Capital do novo Estado, fato que corroborou ainda mais para o esvaziamento econômico do município 9 .

A condição fronteiriça durante todo o período compreendido entre os anos trinta e início dos oitenta é conformada em dois

9 Com crise na cidade e cheia no campo, houve um êxodo rural e emigração - a população urbana de Corumbá, conforme os dados censitários, em 1970 era de 51.146 em 1980: 67.561, enquanto a população total era em 1970: 81.887 e em 1980: 81.129. 
OLIVEIRA, T.C.M. \& ESSELIN, P.M. Localizando as condições pretéritas...

formatos: uma, majoritária, movida por fatores conjunturais e outra, mais modesta, movida por necessidades internas.

Há um interesse por parte do Governo brasileiro, após a chegada de Vargas ao poder, de estreitar as relações diplomáticas com o Paraguai e com a Bolívia tão deterioradas pelos conflitos de outrora, como forma de instituir um equilíbrio geoestratégico ao papel exercido pela Argentina no continente ${ }^{10}$. Fruto desta aproximação, pelo lado Brasil-Bolívia, dois elementos preenchiam a pauta de entendimentos: colocar em execução o Tratado de Limites e Comunicação Ferroviária entre o Brasil, e a Bolívia assinado de 1928, com assinatura de mais dois tratados: vinculação ferroviária cujo objetivo central foi a construção da ferrovia Santa Cruz-Corumbá e o Tratado de Roboré, de 1958.

O propósito geopolítico da construção da Ferrovia Santa CruzCorumbá $^{11}$ eram: um, fazer a ligação da Bolívia com o sudeste brasileiro - aproveitando a chegada dos trilhos em Corumbá em 1953 - antes que os trilhos argentinos fizessem a ligação da Bolívia com Buenos Aires, o que foi obtido; e dois, do ponto de vista

10 Assunto tratado com mais detalhe no nosso livro "Fronteiras Esquecidas".

11 A Comissão Mista Brasileira-Boliviana criada para a construção da Ferrovia, foi instalada em 1938, mas a ferrovia chegou a Sant Cruz de la Sierra em janeiro de 1955 chegando antes, portanto, da Ferrovia argentina Santa Cruz-Yacuiba em 1957. Entretanto somente em 1970 o trecho total de Corumbá está Santa Cruz de la Sierra foi concluída plenamente (ver: Soares, 1975). 
OLIVEIRA, T.C.M. \& ESSELIN, P.M. Localizando as condições pretéritas...

geoeconômico viabilizar a saída-do-papel do Tratado de Saída $e$ Aproveitamento do Petróleo Boliviano objetivo não alcançado ${ }^{12}$.

Enquanto o Tratado de Roboré, com seus dez convênios, um protocolo preliminar e vinte notas reversais, teve como objetivo, traçar uma “... negociação global de molde a resolver todos os assuntos entre o Brasil e a Bolívia e apagar ressentimentos e suspeitas" (SOARES, 1975 p.155).

Dos dez Convênios inseridos no Tratado, cinco ${ }^{13}$ estabeleciam novos parâmetros de convivência comercial entre os dois países e, instituíam condições especialmente vantajosas para a população fronteiriça, particularmente para a fronteira em tela. Todavia, o Tratado de Roboré era exageradamente grande para ser implementado em sua plenitude. O seu propósito de liquidar todo e qualquer detalhe relacionado às velhas questões de limites brasileiro-boliviano, consolidou-o como um grande feito diplomático.

Estes elementos ditados pela ordem conjuntural tiveram impactos distintos no tabuleiro social daquela fronteira. De forma concreta, somente a ferrovia (Corumbá-Santa Cruz) cumpriu papel ativo no contexto fronteiriço, porém de forma parcial, possibilitando o nascimento e/ou crescimento de vários pequenos núcleos urbanos ao longo do seu trecho; destes, o mais emblemático é Puerto Quijarro, uma cidade que cresceu em função

12 Por motivos que envolve o nascimento da Petrobras e a guerra entre os trustes do petróleo americano (coordenados pela Standard Oil) e angloholandês (coordenado pela Shell), o petróleo boliviano nunca chegou ao Brasil (ver mais em Valarino, 2006).

${ }^{13}$ Convênio comercial; Convênio de Tráfico Fronteiriço; Convênio de Trânsito Livre; Convênio de Intercâmbio Cultural; Convênio para o Estabelecimento, em Corumbá, de Entreposto de Depósito Franco. 
OLIVEIRA, T.C.M. \& ESSELIN, P.M. Localizando as condições pretéritas...

da ferrovia - contudo não ditaram nenhum crescimento importante até os anos oitenta; e, uma embrionária circulação comercial entre São Paulo e Santa Cruz de la Sierra mesmo sem possuir destaque até os anos noventa, abriu perspectivas econômicas para efetivação de um comercio fronteiriço de reexportação.

Com relação ao Tratado de Roboré, do ponto de vista interno, ele não teve unanimidade. Segundo entrevistas com viventes e folheando alguns jornais da época percebe-se que a relevância dada pelo conjunto da sociedade era muito restrita. Disse certo entrevistado que "Corumbá se sentia autossuficiente naquela época" (sic et simpliciter) com relação a sua condição de desenvolvimento. Não há registros de iniciativas dos empresários regionais em abrir flancos no sentido de estreitar relações comerciais com a Bolívia. Tal situação se altera consistentemente, após dez anos passados da assinatura do Tratado.

Como aludido, na contramão do "milagre brasileiro" Corumbá viu esvaecer uma riqueza industrial criada nos vinte anos passados. A partir dos anos setenta que se viu foi uma corrida em torno das possibilidades de aproximação protocolar com a Bolívia, com tentativas, inclusive, de reavivar o Tratado de Roboré.

Em primeiro momento, por iniciativa dos corumbaenses é instituido um Consórcio intermunicipal para o desenvolvimento do pantanal (CIDEPAN) que envolvia quinze municípios do velho Mato Grosso, em 1970. Este Consórcio (que, ante o que se observa somente teve significado em Corumbá), possuía a visível intenção de construir instrumentos para tentar dar respostas ao processo eminente de decadência regional, praticamente não faz menção a questão fronteiriça na sua origem.

Tantas eram as dificuldades que pouco mais tarde em meados da década de setenta, o ex-presidente Ernesto Geisel, elegendo a agropecuária como uma das prioridades do seu 
OLIVEIRA, T.C.M. \& ESSELIN, P.M. Localizando as condições pretéritas...

governo, resolveu criar o Programa de Desenvolvimento do Pantanal (PRODEPAN), cujo conjunto de medidas visava acelerar o processo de desenvolvimento e o aproveitamento das potencialidades da planície pantaneira, reconhecidamente enfrentando grandes dificuldades naquele momento (PRODEPAN, 1974).

Entrementes, pouco mais à frente, "Iniciou um trabalho de maior aproximação com os bolivianos da área e com o Governo do Estado ..." (DIAS-PINO e CUNHA, s.d, s/p) cujo o horizonte era ampliar as relações comerciais com Santa Cruz de La Sierra, conseguindo concretizar de uma ousada agenda de locução diplomática ${ }^{14}$. Dentre elas há que se destacar o encontro Banzer e Medici em Corumbá (abril de 1972). O documento intitulado "Acordo Brasil Bolivia para uma América Latina melhor", entre outros assuntos, trazia a assinatura ( Item 3) de um Tratado de Vinculação Rodoviário para construção de uma Ponte de ligação entre Vila Epitácio (Br) e Cobuja (Bo),colocação de serviço de balsa no Rio Mamoré para facilitar o trânsito entre Guayaramirin (Bo) e Guajará Mirin (Br), e construção de uma ponte sobre o Arroio Concepción para melhor ligação de Corumbá a Puerto Suarez; a constituição de um grupo de trabalho visando à factibilidade de criação de complexos industriais bolivianobrasileiro para aproveitamento dos recursos naturais; e (no item 5) continuação das negociações entre Petrobras e YPFB para aproveitamento de hidrocarbonetos da Bolívia.

14 17.03.72 - Memorial de Puerto Suarez; 04.04.1972 - encontro entre Médici e Banzer em Corumbá; 27 a 29.11.72 - visita do Governador Fragelli a La Paz; 22.05.74 - encontro entre Geisel e Banzer em Cochabamba; setembro de 74 - encontro em Corumbá dos Governadores de MT e do Departamento de Santa Cruz, localizando as mais importantes. 
OLIVEIRA, T.C.M. \& ESSELIN, P.M. Localizando as condições pretéritas...

Como se observa, esse Acordo - que mais aparentava uma "carta de intenções" - tratava, em termos práticos, de beneficiar diretamente à integração fronteiriça com a ponte sobre o arraio Bahia na fronteira Bolívia-Acre, com a balsa sobre o rio Mamoré na fronteira Bolívia-Rondônia e a ponte sobre o arroio Concepción na fronteira em estudo.

Um pouco mais contundente são as Sugestões contidas na Nota Conjunta dos Governadores José Fragelli (Mato Grosso) e Heberto Lladó (Santa Cruz) que visavam solucionar as condições de tráfego na Estrada de Ferro Corumbá-Santa Cruz a fim de permitir a ampliação de circulação de dois para três dias da semana; solucionar a navegabilidade entre a Baia Cáceres, no Canal Tuiuiu e Tamengo; além de indicar que a ELETROBRAS fornecesse energia para as cidades bolivianas, postular redução de tarifas alfandegárias, criar câmaras de comercio, entreposto aduaneiro, invocando o espirito do Tratado de Roboré para incentivar o comércio transfronteiriço. Porém, um ponto chama atenção. O Item IV da Nota, que solicita um convênio ente os dois países no sentido de permitir o ingresso reciproco do gado - de lado a lado - durante as "inundações e as estiagens que ameacem de padecimento os seus rebanhos". O fato da Bolívia ter uma parte menor que a parte brasileira de áreas inundáveis, a questão, em síntese, beneficiava unicamente os brasileiros, inclusive sobremaneira aqueles que possuíam terras na Bolívia.

Por final, na família dos protocolos está o Convênio assinado pelos Presidentes Geisel e Banzer, em Cochabamba em maio de 1974. Neste, o sonho perdido por Corumbá aparece com maior transparência. Nele há um reforço dos elementos constantes na "Ata de cooperação no campo dos hidrocarbonetos", de setembro de 1973, e a "Ata de reunião sobre cooperação e complementação industrial" subscrita em La Paz, em abril de 1974. Com onze 
OLIVEIRA, T.C.M. \& ESSELIN, P.M. Localizando as condições pretéritas...

Artigos e três Anexos o Convênio avigora uma possível "implantação de um polo industrial de desenvolvimento na região sudeste da Bolívia, como base no aproveitamento do gás natural boliviano e das diversas matérias-primas existentes na região." (Artigo I), deixando explícitos os setores a ser incentivados: siderurgia, petroquímica (fertilizantes), cimento, geração de energia, infraestrutura e compra de gás natural. Assim como também explicita no Artigo IV, inciso 2 do Acordo de Cooperação e Complementação Industrial entre Brasil e Bolívia, que: "O governo do Brasil, se compromete a garantir mercado para os produtos industriais do pólo de desenvolvimento boliviano."

Considerando o exposto. Corumbá se aparelha de intenções e protocolos que, à exceção da ponte sobre o Arroio Concepción (início dos setenta) e do gás boliviano (vinte e cinco anos mais tarde) se tornaram realidade.

Isto não permite dizer que a pequena relação funcional de vizinhança entre Corumbá com as cidades bolivianas não tenha ocorrido e não tenha se intensificado. Estas relações que provocam verdadeiras integrações estiveram ativas, em especial com relação a dois fatores: a utilização de mão de obra boliviana, não qualificada, em serviços domésticos, construção civil e oficinas mecânicas; e a compra de produtos de reexportação nas poucas casas do ramo em Puerto Suarez. Mas, a intensificação deste processo de integração funcional estava limitada, em primeiro plano, à reduzida população no lado boliviano. Corumbá possuía, conforme os Censos, nos anos setenta, conforme Censos, uma população urbana de 51.146 habitantes, enquanto no lado boliviano a população urbana não chegava a três mil, ou seja, nos contornos de $6 \%$ da população de Corumbá, e, se contando a população de Ladário este percentual desabava para menos de $4 \%$. 
OLIVEIRA, T.C.M. \& ESSELIN, P.M. Localizando as condições pretéritas...

Também já era sentida a presença de bolivianos na cidade de Corumbá (3.767 segundo Censo-70, 4,6\% da população ${ }^{15}$ ), ocorrendo atendimento de bolivianos no hospital de Corumbá, nos anos setenta, por exemplo, ainda que em número pouco significante em relação ao total (menos de 2\% do total), segundo dados da Santa Casa de Corumbá ${ }^{16}$; bem como, a presença de poucos vendedores ambulantes bolivianos. Igualmente pequena, mas já presente, relação institucional entre a Prefeitura de Corumbá e a Alcaldía de Puerto Suarez e Puerto Quijarro, notando-se nos arquivos da Prefeitura, alguns convites aos vizinhos alcaides para datas comemorativas.

Esta aproximação levou a um fato inusitado e muito emblemático com relação aquelas cidades. Antes da metade da década de setenta aquela fronteira boliviana não possuía luz elétrica; ao mesmo tempo o Brasil não possui nenhum Tratado de compra e venda de energia com nenhuns pais vizinhos - o primeiro será o de Itaipu com o Paraguai -, o que impedia a venda formal de energia da CEMAT (Estatal Centrais Elétricas Matogrossense) à Bolívia. A inventiva solução encontrada pela Prefeitura e pela Estatal foi levar até a fronteira (margem direita do arroio Concepción) o relógio de energia instalado no Consulado da Bolívia em Corumbá, onde, a partir dele (relógio) puxava-se energia até as casas das cidades bolivianas, e seus consumidores rateavam a conta, ao final do mês, com o Consulado. Esta

15 Seguramente havia mais bolivianos no lado brasileiro do que no lado boliviano daquela fronteira. Segundo Souchaud (2008 p. 26) “...a migração boliviana em Corumbá e um fenômeno antigo (...) se mantem importante até a primeira metade dos anos sessenta e logo começou um lento processo de diminuição."

${ }^{16}$ Dados cedidos por Lauter Serra, Diretor da Santa Casa nos anos oitenta. 
OLIVEIRA, T.C.M. \& ESSELIN, P.M. Localizando as condições pretéritas...

gambiarra criativa e solidária funcionou com um conhecimento tácito de todos os órgãos públicos até o final dos anos setenta ${ }^{17}$.

\section{Localizando as condições do pretérito perfeito - do protocolar à fronteira vibrante.}

Depois de quase duas décadas de morosidade econômica um novo clima paira sobre cidades da fronteira, novos ventos vindos do oeste sopraram em direção daquela fronteira.

A partir do início dos anos oitenta os EUA, através da Agência Antidrogas do Governo Americano (DEA), vinham acompanhando de perto a produção da cocaína na Bolívia, um dos maiores produtores dessa droga no mundo, estabelecendo uma série de ações estratégicas de combate à ampliação do plantio de drogas naquele país. Duas ações, em particular, surtiram muito efeito: uma intensa pressão diplomática sobre o governo boliviano e, outra, forçando o Banco Mundial estabelece uma linha de crédito específico, carreando investimentos para o comércio, para a indústria e, principalmente, para agricultura no Departamento de Santa Cruz permitindo um rearranjo produtivo regional apartado da coca.

O Governo boliviano, por sua vez, informado dos feitos provocados pela presença de rasileiros no Paraguai, com o sucesso da modernização da agricultura e da pecuária naquele país, procurou alguns empresários brasileiros para investirem no país e transformarem o campo boliviano em um setor mecanizado e competitivo. Seguindo o mesmo padrão paraguaio ofereceu terras

${ }^{17}$ Fato contado, em entrevista, por Moyses dos Reis Amaral, médico, Secretário de Saúde e Educação de Corumbá entre 1970 e 1974, um cuidadoso estudioso da região e mestre em Estudos Fronteiriços. 
OLIVEIRA, T.C.M. \& ESSELIN, P.M. Localizando as condições pretéritas...

aos empresários brasileiros (cujo contato central foi o empresário Olacir de Moraes - o rei da soja) onde, o investidor poderia adquirir terras férteis e baratas, algumas devolutas, com garantias e subsídios governamentais, condicionado a aportar uma agricultura moderna capaz de quebrar a estrutura de quase subsistência ali existente (ESSELIN, OLIVEIRA e OLIVEIRA, 2012). Mais ainda. Segundo Domenach e Celton (1996), o Governo boliviano a partir do início dos anos noventa passou a desestatizar as suas minas, por efeito, passou a transferir trabalhadores, provocando desemprego, barateando a mão-de-obra e a precarização do trabalho.

Rapidamente, em menos de um lustro, Santa Cruz de la Sierra passou a ser a cidade mais dinâmica de toda Bolívia. Provocado pela implementação de uma nova agricultura, nascimento de indústrias e expansão das atividades comerciais, o Departamento de Santa Cruz, muito desindustrializado até então, passou a requerer uma quantidade de mercadorias sem precedentes. Essas mercadorias possuíam duas frentes de entrada no país: do Chile (produtos chilenos e outros importados pelos Portos de Arica e Iquique) e do Brasil passando pela fronteira em questão.

Não especificamente por este motivo, mas também por conta dele, em 1985 praticamente é concluída a pavimentação das BR 262, trecho Corumbá-Miranda ${ }^{18}$, o que permitiu que os produtos bolivianos de exportação, sobretudo soja dos arredores de Santa Cruz, fossem transportados até o Porto de Santos.

18 Ficaram faltando ainda $21 \mathrm{~km}$ mas com boa condição de trafego e a ponte sobre o Rio Paraguai, fazendo com que a travessia permanecesse sobre balsas até o final dos noventa. Não há documentação suficiente para afirmar, mas os fatos permitem deduzir que os empresários brasileiros fizeram constante pressão para o asfaltamento desta rodovia. 
OLIVEIRA, T.C.M. \& ESSELIN, P.M. Localizando as condições pretéritas...

Em todos os sentidos, foi se fortalecendo um Corredor ${ }^{19}$ entre São Paulo e Santa Cruz, onde a fronteira Corumbá, Puerto Quijarro e Puerto Soares passaram a desempenhar papel de destaque como porto de desembaraço aduaneiro, transbordo de mercadorias, estocagem, e pontos de intermediação. Ali, paradoxalmente, a não pavimentação da carreteira Santa CruzPuerto Suarez e as condições desconfortáveis e burocráticas do transporte ferroviário foram marcantes para o desempenho das condições elencadas para a fronteira.

Estes elementos irão redesenhar a região em todos os seus aspectos. Imprimem uma nova lógica aos vetores econômicos regionais. Primeiro, a condição protocolar que era meramente de papel agora se efetiva com um crescimento que impressiona pelo ritmo e volume de caminhões estacionados na Rua Joaquim Murtinho (tradicional local das transportadoras). Outro sintoma é o nascimento da AGESA (Armazéns Gerais Alfandegados de Mato Grosso do Sul S/A) em 1988 e sua efetiva participação no desembaraço aduaneiro diminuindo o tempo de permanência da carga no recinto aduaneiro para entorno de $48 \mathrm{~h}$ (BATISTA da SILVA, 2013), respondendo com a maior referência de intensificação dos fluxos formais em direção a Bolívia. E, por fim o comercio de gás com a implantação do gasoduto Brasil-Bolívia em 1997 e sua efetivação em 2000 respondem em definitivo pelo influxo das transações de jure. Aquela fronteira se restabelece definitivamente como uma fronteira protocolar, com alto fluxo de

${ }^{19}$ Ao estilo - guardando as pertinentes proporções - Corredor Interstates entre Montreal (Ca) e Monterrey (Mx); Corredor Camino Real de Regina $(\mathrm{Ca})$ até Cidade do México (Mx), entre outros, a como se refere Wong-González, 2005. 
OLIVEIRA, T.C.M. \& ESSELIN, P.M. Localizando as condições pretéritas...

trânsito formais e com baixo fluxo de trânsito funcionais não ilícitos (Cf. OLIVEIRA, 2009). Porém, por pouco tempo.

Esta condição de transbordo de mercadoria de uma ponta-aoutra do Corredor, por efeito, alargou os horizontes dos fluxos econômicos regionais. No segundo lustro dos anos oitenta o caminho aberto em larga escala para mercadorias do Brasil para a Bolívia, também, dialeticamente, suscitou alargar os caminhos contrários da Bolívia para o Brasil com produtos, tanto de origem boliviana, (de couro, sobretudo), quanto de outras origens (quase todos os outros), com preços altamente competitivos em relação aos executados no lado brasileiro (OLIVEIRA, 1998).

O movimento e participação do comercio local brasileiro e boliviano no processo passassam a ser visível e muito consistente, onde as melhores expressões são: o nascimento da "feirinha" no distrito de Arroyo Concepción, a participação dos comerciantes de Corumbá no comercio de exportação e o nascimento do shopping de Puerto Aguirre.

Além da tradicional feirinha (também cunhada de "shopping chão"), que no seu início, em 1987, era apenas um amontoado de barracas de lonas, um comércio ao estilo "sweat-shops", dispostas em um recinto desagradavelmente insalubre, vendendo desde produtos de qualidade proveniente de Santa Cruz de la Sierra, como casacos de couro, até produtos falsificados como sapatos e roupas, de reexportação; também se pontua o Shoping Aguirre, um pequeno porto franqueado nascido em 1988, com várias pequenas lojas para venda de produtos de reexportação, com a clara função de atender a classe média regional. Em ambos os casos a global production network ancorava seus produtos naquele nuvioso mercado fronteiriço.

Em Corumbá, se existe uma categoria de comerciantes que passou quase incólume à crise da cidade nos anos setenta foram os 
OLIVEIRA, T.C.M. \& ESSELIN, P.M. Localizando as condições pretéritas...

palestinos. Quando veio à tona a possibilidade do mercado local exportar para a Bolívia, não foram os exportadores de alhures que iniciaram a corrida e sim estes comerciantes ${ }^{20}$ (OLIVEIRA, 2008). Entretanto essa dinâmica estava assentada sobre a fragilidade de um comércio exportador de capital local reduzido, fator preponderante para o afastamento daqueles comerciantes no início dos anos noventa. O comércio exportador, nesse período, foi se especializando, das 251 empresas exportadoras em 1988, grande maioria de capital local nas mãos dos palestinos, sobraram menos de quarenta, em 1992, quase todas nas mãos de exportadores de alhures $^{21}$, ao mesmo tempo em que a exportação aumentava progressivamente.

As condicionantes dadas pelo volume de capitais proporcionaram novos fluxos migratórios para a região, especialmente para o lado da Bolívia, mais dinâmico, fazendo crescer o volume populacional ${ }^{22}$ com migrações oriunda tanto

20 A participação deste setor foi de tamanha envergadura que mudou a paisagem do centro da cidade (em especial Rua 13 de junho) com o apinhado de caixas nas calçadas, e a ampliação para cima das lojas (moradia-de-negócio) maculando o conjunto arquitetônico. Rapidamente as "casas" foram se transformando em exportadoras e o trânsito infernizava os transeuntes.

${ }^{21}$ A presença do local nesta atividade, quando permaneceu, ficou restrita a condição de "representação".

${ }^{22}$ Se a população não cresceu significativamente em Corumbá - menos de 1\%/ano ente 1980 e 2010 - ao menos parou de decrescer em número absolutos; enquanto o crescimento do lado boliviano, segundo o Instituto Nacional de Estatistica da Bolívia (INE), foi de, em média, $3,6 \%$ ao ano no mesmo período. Se em 1970 os bolivianos representavam apenas $6 \%$ na fronteira, hoje já ultrapassaram $30 \% \mathrm{em}$ relação a população de brasileiros. 
OLIVEIRA, T.C.M. \& ESSELIN, P.M. Localizando as condições pretéritas...

doutros lugares da Bolívia quanto de bolivianos de Corumbá23; estimulando, por sua vez, a conexão do território em redes técnicas formais, funcionais e extralegais; e, marchetando, até com rapidez, uma outra identidade territorial reconstruída sob um novo marco de referência fundamentalmente geográfico, solidificando novas regras, novos comportamentos a partir de outras relações de interdependências espaciais.

A fronteira Brasil-Bolívia em estudo, já adentra os anos noventa sob a égide de uma forte convivência socioeconômica submetido a uma lógica territorial domada pela fluidez de transações legais; mas, submetida a condicionantes territoriais produzidas e conquistadas pelo esforço de diferentes escalas de relações funcionais apropriadas pela população local; do mesmo modo que a fronteira tipicamente protocolar foi cedendo lugar a uma oura fronteira muito mais opulenta, complexa e vibrante.

\section{Localizando o complexo sistema urbano da Fronteira Vibrante - uma conclusão.}

Em todos os aspectos há, no presente, uma nova funcionalização do território da conurbação Corumbá-LadárioPuerto Quijarro-Puerto Suarez que dista muito das condições herdadas até o final dos anos setenta. Há uma nova "produção do espaço" no dizer de Lefreve (1978), criado a partir de controles diferentes dos fluxos, estoque, hierarquias e do controle social.

${ }^{23}$ Se em 1970 eram 3.767 bolivianos em Corumbá em 1980 eram 1.692, em 1990: 1,186 em 2000: 1.093, ou seja, há uma transferência de bolivianos do município de Corumbá atravessando de volta a fronteira para a Bolívia (SOUCHAUD, S. e BAENINGER, R. 1998a). 
OLIVEIRA, T.C.M. \& ESSELIN, P.M. Localizando as condições pretéritas...

A lógica estrutural da cidade de Corumbá que outrora obedeciam a um ordenamento territorial quase monolítico ${ }^{24}$ foi se adaptando a uma lógica de aproximação urbana voluntarista e difusa com Puerto Quijaro.

A atual condição fronteiriça está marcada por profundas assimetrias (especialmente socioculturais), e, está, desde os anos oitenta, possibilitando a edificação de uma territorialidade fronteiriça. As circulações advindas das complementaridades capital, trabalho, terra e serviços segundo House (1980), e mais a cultura entre brasileiros e bolivianos vêm materializando um processo com signos novos e matizes radiantes de integração, interação, rebeldia e conflito. Permitindo dizer que o cotidiano fronteiriço daquela conurbação está sendo submetida, em todos os ângulos, a interrogações múltiplas, igualmente perturbadoras, ricas e graves.

O núcleo urbano de Puerto Quijarro, cujo dinamismo estava circunscrito a estação ferroviária,foi permitindo uma expansão de seu traçado para mais próximo do Corumbá através do crescimento abrupto de Arroyo Concepción, seu distrito, onde a cidade é fundamentalmente comercial.

Já em Corumbá, cujo traçado citadino obedecia a concepção militar de distanciamento da linha limítrofe, vem sendo alterada pelo seu oposto, cada vez mais se aproximando da Bolívia: seja por meio do adensamento espremido entre o Canal do Tamengo e o aeroporto; seja pelo contorno do aeroporto pelo bairro da Pedreira; seja pelo anel rodoviário; ou ainda, pela aproximação dos assentamentos rurais do Tamarineiro I e Tamarineiro II, Paiolzinho e Mato Grande que se separam - ou melhor, se juntam - , na franja

24 A palavra "monolítico" está aqui entendida como um sistema que possui uma interface bem definida em termos de parâmetros e resultados. 
OLIVEIRA, T.C.M. \& ESSELIN, P.M. Localizando as condições pretéritas...

de fronteira com os assentamentos de El Carmen de la Frontera (Bo), pelo traçado da Estrada do Tamarineiro (SABATEL e COSTA, 2013).

De tal maneira, foi se configurando uma junção urbana que compartilha, sucessivamente, equipamentos sociais, fortifica a abrangência dos fluxos (Quadro 1, abaixo) e força a mobilização de recursos para aquilatar acessibilidades, remover obstáculos e custear uma porosidade com níveis desejáveis de convivência social, coletiva e institucional.

Quadro 1: Fluxos, impactos e barreiras que impedem a consolidação, fluidez (ou controle no caso do tráfico) na Fronteira em estudo ${ }^{25}$.

\begin{tabular}{|c|c|c|c|}
\hline $\begin{array}{c}\text { Tipo de } \\
\text { Fluxo } \\
\text { predomin } \\
\text { ante }\end{array}$ & $\begin{array}{c}\text { Direcão } \\
\text { Dimensão e impactos territoriais }\end{array}$ & Barreiras \\
\hline $\begin{array}{c}\text { Comercio } \\
\text { urbano }\end{array}$ & Ambas & $\begin{array}{l}\text { Fortíssimo. Comércio funcional de compra e venda de } \\
\text { produtos de utilidade cotidiana pelas duas populações, } \\
\text { com impactos (positivos e negativos) de grande } \\
\text { intensidade em ambos os lados. }\end{array}$ & Fiscais. \\
\hline $\begin{array}{c}\text { Transporte } \\
\text { interurbano } \\
\text { de pessoas }\end{array}$ & Ambas & $\begin{array}{l}\text { Forte quando individual e fraco quando coletivo. Com } \\
\text { fortes impactos nos equipamentos urbanos, controle de } \\
\text { trânsito e na valorização imobiliária das cidades de } \\
\text { Corumbá e Puerto Quijarro e Puerto Suarez. } \\
\text { Performance socioeconômica muito significativa. }\end{array}$ & \\
\hline
\end{tabular}

${ }^{25}$ Inspirada (e adaptada) no trabalho de Nijkamp e Batten (1990) e Medeiros (2006) 


\section{OLIVEIRA, T.C.M. \& ESSELIN, P.M. Localizando as condições pretéritas...}

\begin{tabular}{|c|c|c|c|}
\hline Migrações & $\begin{array}{l}\text { Da } \\
\text { Bolívia } \\
\text { para } \\
\text { Brasil e } \\
\text { Bolívia }\end{array}$ & $\begin{array}{l}\text { A lado boliviano e fortemente impactado pelo volume } \\
\text { de migrações doutras regiões da Bolívia para aquela } \\
\text { fronteira. Para Corumbá a migração boliviana é } \\
\text { moderada com impactos mais culturais do que } \\
\text { econômicos. }\end{array}$ & $\begin{array}{l}\text { Física } \\
\text { (Insuficiênci } \\
\text { a de } \\
\text { Infraestrutura } \\
\text { urbana) }\end{array}$ \\
\hline $\begin{array}{l}\text { Trabalho } \\
\text { pendular }\end{array}$ & $\begin{array}{c}\text { Da } \\
\text { Bolívia } \\
\text { para o } \\
\text { Brasil }\end{array}$ & $\begin{array}{l}\text { Muito forte, em especial de feirantes e trabalhadores da } \\
\text { construção civil. Há impactos de toda ordem: legal, } \\
\text { social, cultural e trabalhista. }\end{array}$ & Institucional \\
\hline $\begin{array}{c}\text { Transporte } \\
\text { de carga }\end{array}$ & Ambas & $\begin{array}{l}\text { Fortíssimo o ritmo muito elevado de exportação do } \\
\text { Brasil para a Bolívia; e sazonal de utilização dos Porto } \\
\text { de Santos para produtos de exportação da Bolívia. Com } \\
\text { impactos nos equipamentos urbanos, no movimento } \\
\text { turístico: bares, restaurantes, hotéis, prostituição, etc. }\end{array}$ & $\begin{array}{l}\text { Congestiona } \\
\text { mento } \\
\text { (Desembaraç } \\
\text { o aduaneiro } \\
\text { lento) }\end{array}$ \\
\hline Culturais & Ambas & $\begin{array}{l}\text { Moderada, pequena ante ao volume de outras relações. } \\
\text { As festas religiosas, turísticas e comemorativas são } \\
\text { pouco compartilhadas, assim como as festas de caráter } \\
\text { privado. É fraco também na gastronomia e nas } \\
\text { artesanias. Ainda há pouca coesão socioeconômica } \\
\text { neste aspecto. }\end{array}$ & $\begin{array}{c}\text { Culturais } \\
\text { (Preconceito } \\
\mathrm{e} \\
\text { Convenciona } \\
\text { lismos) }\end{array}$ \\
\hline Sociais & $\begin{array}{c}\text { Da } \\
\text { Bolívia } \\
\text { para o } \\
\text { Brasil }\end{array}$ & $\begin{array}{l}\text { Forte, especialmente em se tratando da utilização dos } \\
\text { serviços públicos de saúde, educação e assistência, com } \\
\text { impactos positivos na integração, e negativo, nas } \\
\text { contas públicas do município. }\end{array}$ & $\begin{array}{c}\text { Culturais } \\
\text { (Linguística) }\end{array}$ \\
\hline Ambientais & $\begin{array}{l}\text { Do Brasil } \\
\text { para a } \\
\text { Bolívia }\end{array}$ & $\begin{array}{l}\text { Moderando. Há muita compra de madeira da Bolívia } \\
\text { para moveis e construção (portas janelas, etc.). Com } \\
\text { impactos ainda moderados no meio ambiente, mas com } \\
\text { probabilidades de impactos crescentes no lado } \\
\text { boliviano. }\end{array}$ & $\begin{array}{l}\text { Técnicas } \\
\text { (Ausência de } \\
\text { regulamentaç } \\
\text { ão) }\end{array}$ \\
\hline $\begin{array}{c}\text { Tráfico de } \\
\text { drogas }\end{array}$ & $\begin{array}{c}\text { Da } \\
\text { Bolívia } \\
\text { para o } \\
\text { Brasil }\end{array}$ & $\begin{array}{l}\text { Forte. A quantidade de cocaína apreendida pela Polícia } \\
\text { Federal, a quantidade de encarcerados (homens e } \\
\text { mulheres) nos presídios de Corumbá e a quantidade de } \\
\text { bocas-de-fumo existente na fronteira provocam fortes } \\
\text { impactos sociais na região, aumento da violência, } \\
\text { saúde, desestruturação familiar, etc. }\end{array}$ & $\begin{array}{l}\text { Técnicas e } \\
\text { Institucionais }\end{array}$ \\
\hline
\end{tabular}


OLIVEIRA, T.C.M. \& ESSELIN, P.M. Localizando as condições pretéritas...

Fonte: Com base em dezesseis dissertações do Mestrado em Estudos Fronteiriços e documentação de campo do CADEF.

O Fato é que ...

“... la vecindad geográfica los conduce a entrar en interacciones sociales que no requieren que ninguno ceda a sus respectivas identidades culturales, sino de que hayan tenido la habilidad de desarrollar acuerdos implícitos de carácter operativo, suficientes como para llevar a cabo de manera racional una secuencia conductual de medios afines compatibles" (BUSTAMANTE, 1989 p.11).

... pontuando que, tanto em quantidade, do ponto de vista econômico, quanto em qualidade, do ponto de vista sociocultural, a integração vem produzindo uma nova realidade territorial com elevada complexidade.

Todavia, em tais condições não se observa, (e por certo jamais se observará), a presença de uma ecologia humana única, de um mercado plenamente integrado e de formas unificadas de gestão e planificação urbana (ALEGRIA, 1998), descartando, como efeito, qualquer possibilidade de uniformidade e unificação.

Como se pode apreciar no Quadro-1 os fluxos dominantes naquela fronteira vão da extrema formalidade à extrema funcionalidade - com interesses nada convergentes, e até, com estritas divergências - chegando até as raias da ilegalidade concreta. Contudo, tanto o lado brasileiro quanto boliviano tem alargado as possibilidades para operar acordos operativos no sentido de arrefecer os efeitos barreira (ditas no Quadro-1) e flexibilizar todos marcos regulatórios (dos países), formatando sistemas de regras, exigindo diferentes critérios de avaliação coletiva para a obtenção de legitimidade associada às convenções e 
OLIVEIRA, T.C.M. \& ESSELIN, P.M. Localizando as condições pretéritas...

aos interesses - conforme aludem Max e Oliveira (2009), sem a necessidade de unificar comportamentos culturais.

Nestas condições e termos, a conurbação Corumbá (e Ladário), Puerto Quijarro e Puerto Suarez - em regime de aproximação com os assentamentos rurais - podem ser identificados como complexos urbanos transfronteiriços conforme estabelecido por Dilla Alfonso (2015 p. 27), visto que:

i) compartilham o mesmo ambiente seja urbano, seja por aproximação das cidades, seja pelos fluxos diversos, ou seja rural (como os assentamentos) ou pela utilização dos recursos naturais das margens e das águas da laguna Caceres, Canal do Tamengo e Rio Paraguai;

ii) pelo elevado nível de articulações diversas, aquela junção está bem estabelecida e constituída como entrepot comercial dado pelas diversas interfaces do Corredor São Paulo-Santa Cruz de La Sierra;

iii) possuem, hoje, uma profunda e profícua interdependência econômica com consumos variados de ambos os lados movidos, em parte, pela relação cambial aproveitando-se da economia de arbitragem, acomodando complementariedades sociais (saúde, educação e assistência) marcados pela funcionalidade (Rivas, 2011), e ao mesmo tempo, outorgando externalidades negativas como descontrole do trânsito, especulação imobiliária e tráfico de drogas (contabilizando trezentas boca-de-fumo em Corumbá Cf. Oliveira e Da Costa), 2012 e utilização dos locais como mulas (Oliveira e Linjard, 2013), ainda que as diferenças socioeconômicas entre as cidade sejam abismais;

iv) são profundamente desiguais e assimétricas as culturas presentes, não se observando, ainda, incisivos traços de 
OLIVEIRA, T.C.M. \& ESSELIN, P.M. Localizando as condições pretéritas...

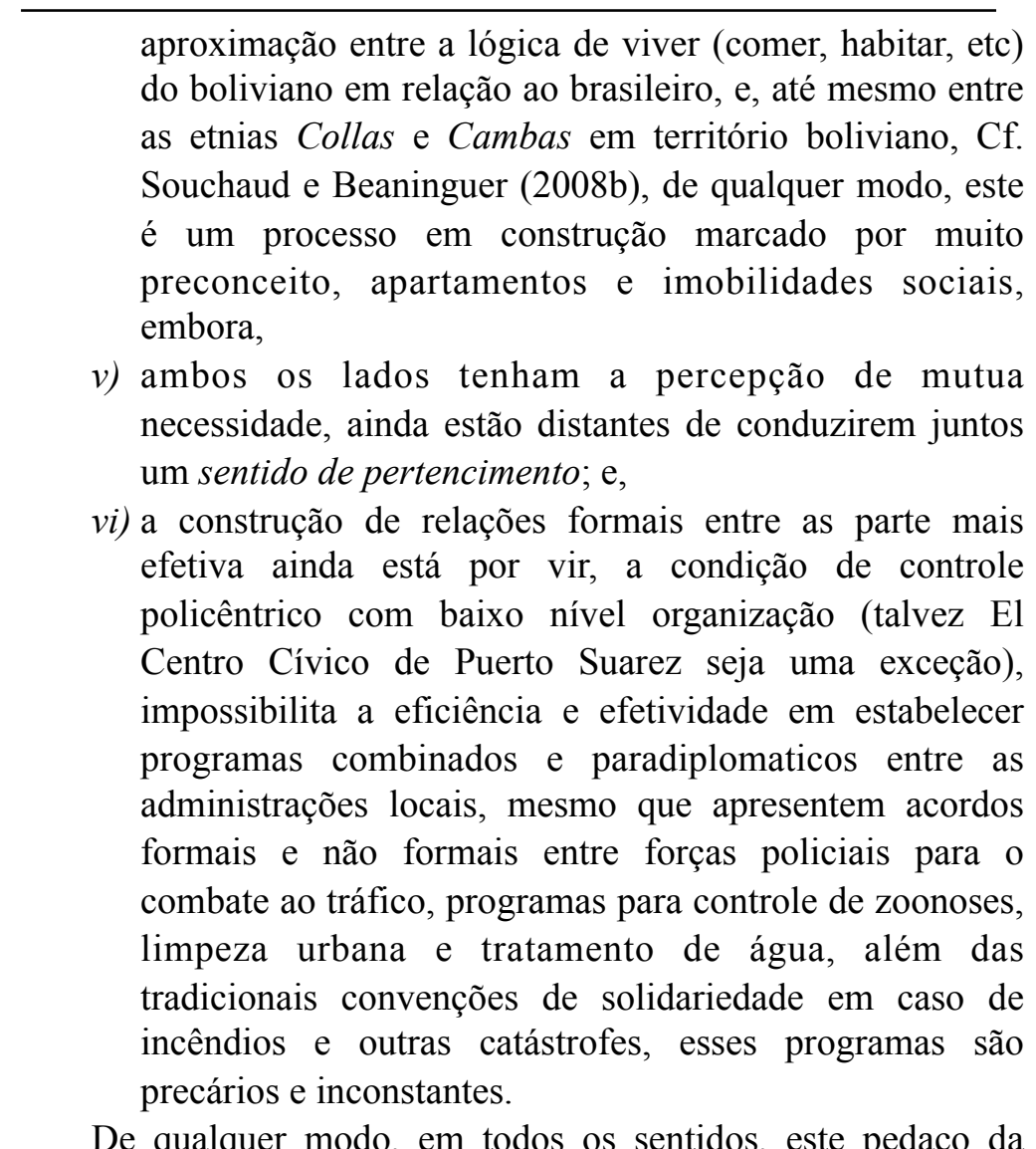

De qualquer modo, em todos os sentidos, este pedaço da fronteira Brasil-Bolívia possui uma história de aproximação marcada por movimentos internos alternando-se entre lentos, longos e abruptos, produzidos sobre contornos territoriais com especificidades únicas, o que lhe confere muita força, capacidade criativa e consistência.

Em igualdade de circunstâncias, trata-se de um território que também foi (e está) regido (e até patrulhado) sob a égide de ações 
OLIVEIRA, T.C.M. \& ESSELIN, P.M. Localizando as condições pretéritas...

exógenas e conjunturais, o que lhe expõe restrições impactantes capazes de abalar sua consistência e exigir esforço adicional da capacidade criativa territorial.

É possível, portanto, aludir que o futuro aponta para este território - progressistamente maleável e perigosamente variante um ritmo crescente de aproximação física do platô urbano de um lado ao outro; um ritmo acelerado nas integrações socioeconômicas e institucionais; um ritmo cadenciado no processo de flexibilização cultural; e, do ponto de vista macroeconômico muitas interrogações devem ser colocadas à mesa, a partir da grande possibilidade de um novo ciclo de retração do mercado mundial com rebatimentos nos crescimentos nacionais, e, com o fim do contrato de compra de gás boliviano por parte do Brasil no ano de 2019.

\section{Referencias bibliográficas}

ALEGRIA, T. La ciudad y los procesos transfronterizos entre México y Estados Unidos. In; Frontera Norte. V.1, n.l (p53-90), 1989.

ALVES, G. L. “ Mato Grosso e a história: 1870-1929 ensaio sobre a transição do domínio da casa comercial para a hegemonia do capital financeiro". In: Boletim Paulista de Geografia. São Paulo: $2^{\circ}$ sem. 1984. $n^{\circ} 61,1984$.

AMORIM, A. Viagens pelo Brasil: do Rio ao Acre - aspectos da Amazônia do Rio a Mato Grosso. Rio de Janeiro, Livraria Garnier, 1917.

BANDEIRA, A. Moniz. A Guerra do Chaco.2000 Disponível em: h t t p : / / w w w. s c i e 1 o.b r / s c i e lo.ph p ? pid=S0034-73291998000100008\&script=sci_arttext. 
OLIVEIRA, T.C.M. \& ESSELIN, P.M. Localizando as condições pretéritas...

BATISTA DA SILVA,L. P. Redes de transporte de mercadorias e fronteira: a logística nas cidades gêmeas de Corumbá. Revista Transporte y Territorio, núm. 9, pp. 141-159. 2013.

BUSTAMANTE, J. Frontera México-Estados Unidos: Reflexiones para un marco teórico. Frontera Norte, vol. I, núm. 1, enero-junio de 1989.

CADAVID, G. Estimativas de custo de produção da pecuária de corte no Pantanal Mato-Grossense. EMBRAPA-UEPAE de Corumbá (Circulat Técnica 3), 1981.

CORRÊA, Lúcia Salsa. Corumbá: um núcleo comercial na fronteira de Mato Grosso 1870 - 1920.Dissertação de mestrado apresentado ao Departamento de História da Faculdade de Filosofia Letras e Ciências Humanas da Universidade de São Paulo. São Paulo, 1980.

COSTA, E.A. e SABATEL,V. Mobilidades humanas e interações sociais entre comunidades rurais na fronteira Brasil-Bolívia. Terr@Plural, Ponta Grossa, v.8, n.1, p. 13-35, jan./jun. 20142013.

CHAMMA, A. Por um Brasil Melhor. s.d.s.ed.

DIAS-PINO, W.e CUNHA, C. Fronteira Viva ,s.e, s/L, s.d,

DILLA ALFONSO, H. Los complejos urbanos transfronterizos en América Latina. Estudios Fronterizos, nueva época, vol. 16, núm. 31, enero-junio de 2015, pp. 15-38.

DOMENACH, H. e CELTON, D. La comunidad boliviana en Cordoba. Caracterización y proceso migratório, Universidad de Córdoba, 1996. 
OLIVEIRA, T.C.M. \& ESSELIN, P.M. Localizando as condições pretéritas...

ESSELIN, P.M. e OLIVEIRA,T.C.O. Índio, gado e blindagens na construção da fronteira sul de Mato Grosso. Boletim Gaucho de Geografia. N. 32, 2006.

ESSELIN, P.M. OLIVEIRA, T.C.M e Oliveira. M.M.O Fronteiras Esquecidas - A construção de Hegemonias nas fronteiras entre os rios Paraguai e Paraná. Campo Grande, Editora da UFGD, 2012.

FURTADO. C. Economia Brasileira. 1954.

HOUSE, J.W. The Frontier Zone. A Conceptual Problem for Policy Makers. In: InternationalPolitical Science Review. 4(1). 456-477, 1980.

LAMOSO, L.P. A Exploração do Minério de Ferro no Brasil e no Mato Grosso do Sul. Tese de Doutorado. FFLCH/USP, 2001.

LEFEBVRE H.De L'État 4. Les contradictions de l'État moderne. Paris: Antropos, 1978.

MAX, C. e OLIVEIRA T.C.M As relações de troca em região de fronteira: uma proposta metodológica sob a ótica convencionalista. GEOSUL. Florianópolis, v. 24, n. 47, p 7-27, jan./jun. 2009.

MEDEIROS, C. A. Introdução. In Geografia de Portugal, Vol. 3, Actividades Económicas e Espaço Geográfico, pp 12-13. Circulo de Leitores, Lisboa, 2006.

MICHELS, I. e OLIVEIRA, T.C.M. Bordas do Pantanal (ocupação, dinamismo e meio ambiente). GEOSUL. Florianopolis, V.15, n.30, jul/dez, 2000.

NIJKAMP, P. e BATTEN, D. Barriers to communication and spatial interaction. In The annals of Regional Science, Bellingham - Vol 24, nº, pp. 233-236. Boston, 1990. 
OLIVEIRA, T.C.M. \& ESSELIN, P.M. Localizando as condições pretéritas...

OLIVEIRA, G. F. e Da Costa,G.V.L Redes ilegais e trabalho ilícito: comércio de drogas na região de fronteira de corumbá/brasil - puertoquijarro/bolívia. Boletim Gaucho de Geografia, BGG 38 pás. 137-156 - maio de 2012.

OLIVEIRA, M.A.M. Tempo, fronteira e imigrantes: um lugar e suas 'inexistências'. In: OLIVERIA, T.C.M. Territorio sem Limites. Edufms, 1995.

OLIVEIRA, T.C.M. e LINJARDI, L.G.S. Carga Pesada das Mulas - Sobre mulheres traficantes na Fronteira Brasil-Bolívia. Revista Ideação, v. $15 \mathrm{n}^{\mathrm{o}} 2.2^{\circ}$ semestre de 2013.

OLIVEIRA, T.C.M. Uma Fronteira para o Pôr-do-Sol-um estudo sobre uma região de fronteira. (Coleção Fontes Novas) Campo Grande: UFMS, 1998.

OLIVEIRA,T.C.M "Frontières em Amérique latine: réflexions méthodologiques". Espaces et Sociétés. Paris: 138 n.3/2009, 18-33p. 2009.

OLIVEIRA, T.C.M. . Os Elos da Integração. In: OLIVEIRA, M.A.M e COSTA, E. (Org.). Seminário de Estudos Fronteiriços. 1 ed. Campo Grande: Editora da UFMS, 2009.

PANTANAL NOVA FRONTEIRA ECONÔMICA: I Encontro do PRODEPAN. Corumbá: Secretaria de Estado de Agricultura de Mato Grosso, 1974.

RIVAS, V. "Yo no soy boliviano yo soy carioco" - sobre línguas e preconceitos na fronteira Brasil-Bolívia. Dissertação de Mestrado. MEF/UFMS, 2011.

SOARES, Álvaro Teixeira. História da Formação das Fronteiras do Brasil. 3 eds., Rio de Janeiro: Conquista, 1975. 
OLIVEIRA, T.C.M. \& ESSELIN, P.M. Localizando as condições pretéritas...

SOUCHAUD S. e BAENINGER, R. Diferenciais da Imigração Boliviana em Corumbá: resultados de pesquisa de campo. Artigo apresentado no Seminário Internacional de Estudos Fronteiriços, Universidade Federal de Mato Grosso do Sul (UFMS), 2008a.

SOUCHAUD, S. e BAENINGER, R. Collas y Cambas do outro lado da fronteira: aspectos da distribuição diferenciada da imigração boliviana em Corumbá, Mato Grosso do Sul. Revista Brasileira de Estudos de População, n²5, vol. 2. 2008b.

VILARINO, Ramon Casas.Os Acordos de Roboré - Brasil, Bolivia e as questões do petróleo, desenvolvimento e dependência no final dos anos 1950. Tese de Doutorado em Ciências Sociais. Pontifícia Universidade Católica de São Paulo. 2006.

WONG-GONZÁLES, P. (2005) “Cooperación y competencia internacional de regiones: hacia nuevas formas de gestión de desarrollo regional binacional" in: OLIVEIRA, T.C.M (Org). Território sem Limites - Estudos sobre fronteiras. Campo Grande: Ed. UFMS.

Recebido em maio de 2015 Aceito em agosto de 2015 